\title{
A method for extraction and LC-MS based identification of carotenoid-derived dialdehydes in plants
}

\author{
Jianing Mi, Kun-Peng Jia, Aparna Balakrishna and Salim Al-Babili*
}

King Abdullah University of Science and Technology (KAUST), Biological and Environmental Sciences and

Engineering Division, The BioActives Lab, Thuwal 23955-6900, Kingdom of Saudi Arabia.

*E-mail: salim.babili@kaust.edu.sa

Running Title: Method for Identification of Carotenoid-derived Dialdehydes 


\title{
A method for extraction and LC-MS based identification of
}

\section{carotenoid-derived dialdehydes in plants}

\begin{abstract}
:
We developed a chemical derivatization based ultra-high performance liquid chromatography-hybrid quadrupole-Orbitrap mass spectrometer (UHPLC-Q-Orbitrap MS) analytical method to identify low-abundant and instable carotenoid-derived dialdehydes (DIALs, diapocarotenoids) from plants. Application of this method enhances the MS response signal of DIALs, enabling the detection of diapocarotenoids, which is crucial for understanding the function of these compounds and for elucidating the carotenoid oxidative metabolic pathway in plants.
\end{abstract}

Key words: Carotenoid-derived dialdehydes, Apocarotenoids, Diapocarotenoids, Chemical derivatization, Arabidopsis, UHPLC-MS

\section{Introduction}

Carotenoids are a large class of mostly $\mathrm{C}_{40}$ terpenoids characterized by an extended conjugated double bond system that enables them to absorb light in the blue-green $(450-550 \mathrm{~nm})$ range of the visible spectrum and to contribute to plant light-harvesting via extending the range of light absorption of the photosynthetic apparatus beyond that of chlorophyll [1-9]. In addition, carotenoids are indispensable photo-protective pigments that prevent destructive oxidation processes by quenching both singlet and triplet state chlorophylls [10-15]. Furthermore, carotenoids are important determinants of the fluidity of plastid membranes and are accumulated in flowers and fruits to attract animals for pollination and seed dispersal $[9,16,17]$. Carotenoid-derived metabolites also exert important biologic functions. Thus, the class of carotenoid-derivatives includes hormones, such as abscisic acid and strigolactone, [18-25], retinoids, i.e. retinal, retinol (vitamin A), and retinoic acid [2628], the fungal pheromone trisporic acid [29,30], the stress signaling molecule $\beta$-cyclocitral [31-33], the recently 
discovered growth regulators anchorene and zaxinone [34,35], pigments, such as crocin in saffron [36], citraurin in citrus fruits [37], and the fungal neurosporaxanthin $[38,39]$, and volatiles, such as safranal $[40,41]$, geranial $[42]$ and $\beta$-ionone $[43,44]$. All of these bioactive metabolites (named apocarotenoids) are generated by oxidative cleavage of carotenoids, which is generally catalyzed by carotenoid cleavage dioxygenases (CCDs) or by nonenzymatic oxidation caused by reactive oxygen species (ROSs) [25,32,45,46]. In Arabidopsis, there are five different types of CCDs. The nine-cis-epoxycarotenoid cleavage dioxygenases (NCED represented by 5 enzymes; NCED2, 3, 5, 6, and 9) are involved in the biosynthesis of abscisic acid, while the four other CCD types, designated as CCD1, CCD4, CCD7, and CCD8 exert different biological functions and have, accordingly, different substrates and regio-specificities $[\mathbf{2 3 , 2 5 , 4 4 , 4 7 ]}$. For example, CCD1 enzymes catalyze the conversion of carotenoids into a plenitude of volatiles, such as geranial, pseudoionone and $\beta$-ionone, and are likely involved in scavenging of destructed carotenoids/apocarotenoids; the Arabidopsis CCD4 converts all-trans- $\beta$-carotene into $\beta$-ionone and all-trans- $\beta$-apo-10'-carotenal and determines carotenoid content; The strigolactone biosynthesis enzyme CCD7 (MAX3) cleaves 9-cis- $\beta$-carotene to form $\beta$-ionone and 9-cis- $\beta$-apo-10'-carotenal, the substrate of CCD8 (MAX4) that forms the central strigolactone biosynthesis intermediate carlactone.

Carotenoid cleavage yields dialdehyde products (DIALs), besides monocarbonyl apocarotenoids that have been in the focus of carotenoid research. Carotenoid-derived DIALs are defined as a class of carotenoid oxidative products incorporating two aldehyde functional groups, which are produced from repeated oxidative cleavage of double bonds within carotenoids or apocarotenoids (Figure 1). Recent in vitro studies showed that several plant and cyanobacterial CCDs can cleave carotenoids or apocarotenoids to produce DIALs. Adrian et al expected that all-trans- $\beta$-apo- $10^{\prime}$-carotenal can be cleaved by CCD8 to form all-trans-4-methyl-2,4,6octatrienedial [48], which has been confirmed in Wang et al's work. Scherzinger et al demonstrated that cyanobacterial retinal-forming enzymes can catalyze the conversion of $\beta$-apo-8'-carotenoids to all-trans-2,6dimethyl-2,4,6-octatrienedial [49]. Ilg et al reported tomato CCDs 1A and 1B convert many apocarotenoid substrates including apo-8'-lycopenal, apo-10'-lycopenal, apo-12'-lycopenal, and apo-15'-lycopenal in in vitro assays, leading to a series DIALs with different carbon chains (e.g. all-trans-2,6-dimethyl-2,4,6,8decatetraenedial, all-trans-3,7-dimethyl-2,4,6,8-decatetraenedial, all-trans-2,6,11-trimethyl-2,4,6,8,10dodecapentaenedial, all-trans-2,6,11-trimethyl-2,4,6,8,10,12-quattuordecahexaenedial, all-trans-2,7,11- 
trimethyl-2,4,6,8,10,12-quattuordecahexaenedial,

all-trans-4,9,13-trimethyl-2,4,6,8,10,12,14sedecaheptaenedial, all-trans-2,6,11,15-tetramethyl-2,4,6,8,10,12,14-sedecaheptaenedial, all-trans-2,6,11,15tetramethyl-2,4,6,8,10,12,14,16-octodecaoctaenedial) [50]. Moreover, studies on the biosynthesis of bixin (also known as annatto, one of the oldest pigment widely used in foods and cosmetics) [51,52] and crocin (the major saffron pigment) [53], demonstrate the role of DIALs as pigments [41,54]. To our knowledge, all carotenoidderived DIALs reported so far were identified from enzymatic in vitro assays that usually produce them in relatively high amounts, which allow their detection by HPLC or LC-MS. However, endogenous DIALs occur at very low levels and are unstable in plants, making their direct detection using present methods very difficult.

Understanding the biological function of DIALs and determining their role in plant carotenoid metabolism require an analytical method that enables sensitive and reliable determination of these compounds. In this work, we developed a chemical derivatization based UHPLC-Q-Orbitrap MS method for the analysis of carotenoidderived DIALs from Arabidopsis. A crude plant DIALs extract is prepared, which is added to a chemical derivatization regent consisting of $10 \mathrm{mg} / \mathrm{mL} N^{2}, N^{2}, N^{4}, N^{4}$-tetraethyl-6-hydrazineyl-1,3,5-triazine-2,4-diamine (T3) methanol solution with $1 \%$ formic acid. Following derivatization, DIALs are detected using UHPLC-QOrbitrap MS.

\section{Materials}

Use HPLC grade reagents for the extraction. All reagents and water used for UHPLC-Q-Orbitrap MS analyses should be LC-MS grade. All LC-MS solvent additives used must be LC-MS grade. All reagents should be kept on ice during extraction. Waste disposal regulations must be meticulously followed.

\subsection{Plant Material Preparation}

1. Arabidopsis seedlings

2. Liquid nitrogen.

3. Microcentrifuge tubes of $2 \mathrm{~mL}$ capacity.

4. Freeze dry system (Labconco FreeZone 6 Liter Console, or equivalent).

5. Bead beater (Biospec Products, INC. Mini bead beater, or equivalent). 
6. Analytical precision balance (Secura® analytical balance, or equivalent).

\subsection{Crude DIALs Extraction}

1. Stock extraction solution: $10 \mathrm{~mL}$ acetonitrile with $0.1 \%$ butylated hydroxytoluene (BHT) (see Note 1) [55]. The stock extraction solution is made to a volume of $10 \mathrm{~mL}$ and can be stored for 1 month at $4{ }^{\circ} \mathrm{C}$.

2. Microcentrifuge tubes of $2 \mathrm{~mL}$ capacity.

3. Ultrasonic bath (Branson 5510EDTH, or equivalent).

4. Refrigerated microcentrifuge (Eppendorf centrifuge 5424R, or equivalent).

5. Concentrator (Eppendorf concentrator plus, or equivalent).

\subsection{DIALs Derivatization}

1. $1 \%$ Formic acid methanol stock solution (see Note 2). The stock solution is made to a volume of $10 \mathrm{~mL}$ and can be stored for 1 month at $4{ }^{\circ} \mathrm{C}$.

2. Stock derivatization solution: $1 \mathrm{~mL}$ of $10 \mathrm{mg} / \mathrm{mL} \mathrm{N}^{2}, N^{2}, N^{4}, N^{4}$-tetraethyl-6-hydrazineyl-1,3,5-triazine-2,4diamine (T3) methanol solution with $1 \%$ formic acid (see Note 3) [56]. The stock derivatization solution is made to a volume of $1 \mathrm{~mL}$ and can be stored for 1 month at $4{ }^{\circ} \mathrm{C}$.

3. Ultrasonic bath (Branson 5510 EDTH, or equivalent).

4. ThermoMixer (HLC Heating-ThermoMixer MHR 23, or equivalent).

\subsection{UHPLC-Q-Orbitrap MS Detection}

1. DIAL standard stock solution: add $1.6 \mathrm{mg}$ all-trans-2,7-Dimethyl-2,4,6-octatrienedial (DIAL10) to a volumetric flask and make up to $10 \mathrm{~mL}$ with methanol (see Note 4). The stock DIAL solution is made to a volume of $10 \mathrm{~mL}$ and can be stored for 3 month at $-20{ }^{\circ} \mathrm{C}$.

2. Ultra-high performance liquid chromatography (UHPLC) solvents: $450 \mathrm{~mL}$ water, $50 \mathrm{~mL}$ acetonitrile, 1 $\mathrm{mL}$ formic acid (solvent A); $450 \mathrm{~mL}$ acetonitrile, $50 \mathrm{~mL}$ isopropanol, $1 \mathrm{~mL}$ formic acid (solvent $\mathrm{B}$ ) (see Note 5). 
3. $1 \mathrm{~mL}$ Syringe (BD $1 \mathrm{~mL}$ Syringe, or equivalent).

4. $0.22 \mu \mathrm{m}$ Syringe filter (Thermo Scientific $4 \mathrm{~mm}$ PTFE syringe filter, or equivalent).

5. 1.5 mL Amber glass vial (VWR, or equivalent).

6. Micro glass insert (VWR $28 \times 5.6 \mathrm{~mm}$, or equivalent).

7. Acquity UPLC BEH $\mathrm{C}_{18}$ column $(100 \times 2.1 \mathrm{~mm} ; 1.7 \mu \mathrm{m}$; Waters $)$ with an Acquity UPLC BEH $\mathrm{C}_{18}$ guard column $(5 \times 2.1 \mathrm{~mm} ; 1.7 \mu \mathrm{m}$; Waters $)$, or equivalent.

8. Dionex UltiMate 3000 UHPLC system (Thermo Scientific) or equivalent.

9. Heated-electrospray Ionization-Hybrid Quadrupole-Orbitrap Mass Spectrometer (HESI-Q-Orbitrap MS, Thermo Scientific Q Exactive Plus) or equivalent.

\section{Methods}

All steps used for extraction and derivatization of DIALs should be carried out under dim light, unless otherwise specified. This method has been optimized for detecting DIALs in Arabidopsis thaliana. Detecting DIALs in other plant species or tissues might require additional optimization.

\subsection{Plant Material Preparation}

1. Collect fresh, 10 days old Arabidopsis seedlings in $2 \mathrm{~mL}$ microcentrifuge tubes and keep them frozen in liquid nitrogen for $5 \mathrm{~min}$ (see Note 6).

2. Transfer tubes with plant material to the freeze-dry system and dry the material for $12 \mathrm{~h}$ (see Note 7).

3. Add 3 beads in each tube after drying. Then transfer tubes in liquid nitrogen for 1 min (see Note 8).

4. Transfer tubes to the bead beater and homogenize plant material for $1 \mathrm{~min}$.

5. Weigh between 25 and $30 \mathrm{mg}$ dry weight plant material in a $2 \mathrm{~mL}$ microcentrifuge tube. Work quickly and cover the weighed material with aluminum foil. Note the exact weight.

\subsection{Crude DIALs Extraction}


1. Prepare the extraction solution by adding $10 \mathrm{mg}$ of BHT to a volumetric flask and make up to $10 \mathrm{~mL}$ with acetonitrile. Keep the extraction solution on ice.

2. Add $0.5 \mathrm{~mL}$ of extraction solution to each tube and mixture gently. Transfer tubes to an ultrasonic bath for the extraction for $15 \mathrm{~min}$ at $25^{\circ} \mathrm{C}$. After that, transfer tubes to a pre-cooled microcentrifuge at 18,000 $\times \mathrm{g}$ for $5 \mathrm{~min}$ at $4{ }^{\circ} \mathrm{C}$. Collect the supernatant and re-extract the pellet with $0.5 \mathrm{~mL}$ of extraction solution. Combine the two supernatants and dry it using a concentrator (see Note 9).

\subsection{DIALs Derivatization}

1. Prepare $1 \%$ formic acid methanol stock solution by adding $100 \mu \mathrm{L}$ LC-MS grade formic acid to a volumetric flask and make up to $10 \mathrm{~mL}$ with methanol.

2. Prepare the derivatization regent by adding $10 \mathrm{mg}$ of $\mathrm{T} 3$ to a volumetric flask and make up to $1 \mathrm{~mL}$ with $1 \%$ formic acid methanol stock solution. Keep the derivatization regent on ice.

3. Add $50 \mu \mathrm{L}$ of the derivatization regent to the DIAL extract and transfer tubes to ultrasonic bath for the sonication of 30 seconds (see Note 10). Than transfer tubes to a thermomixer for the incubation at $37^{\circ} \mathrm{C}$ for $15 \mathrm{~min}$ (Figure 2).

4. Dilute the DIAL derivatization solution with $50 \mu \mathrm{L}$ of $1 \%$ Formic acid methanol stock solution.

\subsection{UHPLC-Q-Orbitrtap MS Detection}

1. Prepare the DIAL standard solution by adding $10.25 \mu \mathrm{L}$ of DIAL10 standard stock solution to a volumetric flask and make up to $1 \mathrm{~mL}$ with methanol (see Note 11). Keep the DIAL10 standard in dark.

2. Prepare the DIAL10 standard derivatization solution: Add $2 \mu \mathrm{L}$ of DIAL10 standard solution and $50 \mu \mathrm{L}$ of the derivatization regent in microcentrifuge tube (see Note 12). Transfer the tube to a thermomixer at $37^{\circ} \mathrm{C}$ for $15 \mathrm{~min}$. Then dilute the solution with $50 \mu \mathrm{L}$ of $1 \%$ formic acid methanol stock solution.

3. Prepare LC-MS sample solution: The DIAL derivatization solution is filtered to $1.5 \mathrm{~mL}$ amber glass vial with micro glass insert using $1 \mathrm{~mL}$ syringe with $0.22 \mu \mathrm{m}$ syringe filter. 
4. Optimize the instrument parameters for detecting DIALs by infusing a DIAL10 standard derivatization solution into the mass spectrometer using the optimization procedure under positive ionization mode. The optimized parameters will be different depending on the used LC-MS instrument, the optimized parameters of an HESI-Q-Orbitrap MS were full MS scan, scan range of 150 to $900 \mathrm{~m} / \mathrm{z}$, resolution of 280,000, AGC target of $3 \mathrm{e}^{6}$, and maximum inject time of $150 \mathrm{~ms}$.

5. Liquid chromatographic separation of DIAL derivatives is achieved with a $\mathrm{BEH} \mathrm{C}_{18}$ column (Acquity UPLC BEH $\mathrm{C}_{18}$ column) using the following LC parameters: column temperature $=35^{\circ} \mathrm{C}$, injection volume $=15 \mu \mathrm{L}$, flow rate $=0.2 \mathrm{~mL} \mathrm{~min}^{-1}$, total run time $=22 \mathrm{~min}$. Use a solvent gradient program starting with a linear gradient from 20 to $100 \%$ solvent B over 15 min, isocratic separation at $100 \%$ B until $18 \mathrm{~min}$, return to initial conditions of $20 \% \mathrm{~B}$ at $19 \mathrm{~min}$ and equilibrate at $20 \% \mathrm{~B}$ until $22 \mathrm{~min}$ (see Note 13).

6. Ionization was achieved using heated-electrospray ionization with an atmospheric pressure ionization source operating under positive ionization mode. The spray voltage was $4,000 \mathrm{~V}$, the sheath gas flow rate was 40 arbitrary units, the auxiliary gas flow rate was 10 arbitrary units, the capillary temperature was $350{ }^{\circ} \mathrm{C}$, the auxiliary gas heater temperature was $400{ }^{\circ} \mathrm{C}$, and the S-lens RF was 50 . For MS/MS, NCE was $20 \mathrm{eV}$. The ionization parameters also need to be optimized for different LC-MS systems.

7. Xcalibur 2.2 software (Thermo Scientific) was used for data acquisition and processing. Identify the DIAL derivatives produced by the DIAL derivatization reaction using high-resolution MS and MS/MS data, confirmed by synthetic DIAL10 standard (Figure 3).

\section{Notes}

1. We usually make a $10 \mathrm{~mL}$ solution by dissolving $10 \mathrm{mg}$ of BHT in $10 \mathrm{~mL}$ acetonitrile in a volumetric flask. Then transfer solution to a new glass bottle and keep it at $4^{\circ} \mathrm{C}$.

2. Prepare $1 \%$ formic acid methanol stock solution by adding $100 \mu \mathrm{L}$ LC-MS grade formic acid to a volumetric flask and make up to $10 \mathrm{~mL}$ with methanol. To decrease evaporation of formic acid, we usually add $2 \mathrm{~mL}$ methanol to the volumetric flask firstly, then add $100 \mu \mathrm{L}$ LC-MS grade formic acid to 
the volumetric flask with methanol using pipette. Lastly, make up to $10 \mathrm{~mL}$ with methanol in the volumetric flask. $1 \%$ Formic acid methanol stock solution should be kept at $4{ }^{\circ} \mathrm{C}$. It is helpful for storage. Use protective clothing, gloves and protection glasses when using formic acid.

3. Prepare the derivatization regent by adding $10 \mathrm{mg}$ of T3 to a volumetric flask and make up to $1 \mathrm{~mL}$ with $1 \%$ formic acid methanol stock solution. The stock derivatization solution is stored for 1 month at $4{ }^{\circ} \mathrm{C}$. To avoid degradation, do not suggest keeping the stock derivatization solution for more than 1 month.

4. Prepare DIAL standard stock solution by adding $1.6 \mathrm{mg}$ all-trans-2,7-dimethyl-2,4,6-octatrienedial (Tokyo Chemical Industry Co., Ltd.) to a brown volumetric flask and make up to $10 \mathrm{~mL}$ with methanol. DIAL is unstable under light or oxygen conditions. In the DIAL stock solution preparation, methanol should be pre-cooled on ice to reduce the amount of oxygen. Work quickly and keep the DIAL standard stock solution in a brown bottle for 3 month at $-20^{\circ} \mathrm{C}$ as soon as possible to minimize degradation.

5. UHPLC solvents were prepared with LC-MS grade regents and water. Mix $450 \mathrm{~mL}$ water and $50 \mathrm{~mL}$ acetonitrile in mobile phase A glass bottle, and $450 \mathrm{~mL}$ acetonitrile and $50 \mathrm{~mL}$ isopropanol in mobile phase B glass bottle, then degas them in ultrasonic bath for $20 \mathrm{~min}$. After that, add $1 \mathrm{~mL}$ formic acid in mobile phase A glass bottle and mobile phase B glass bottle, respectively. The expiry period of mobile phase A and mobile phase B are 5 days and 2 weeks, respectively.

6. Collect fresh Arabidopsis seedlings in $2 \mathrm{~mL}$ microcentrifuge tubes and keep them frozen in liquid nitrogen for $5 \mathrm{~min}$. Work quickly and quench the metabolism in plant materials as soon as possible.

7. Make sure that the freeze-dry system is ready, and plant materials is in a frozen state. It is difficult to dry the plant material if it is in a defrozen state.

8. Transfer tubes with dry plant materials to liquid nitrogen for $1 \mathrm{~min}$. It makes it easier to homogenize plant material.

9. The drying time of the supernatant in a concentrator is not fixed. It depends on the samples number and the liquid volume. It is better to test the drying time, as too long drying time leads to degradation of DIALs. 
10. The sonication of 30 seconds in ultrasonic bath is used to dissolve DIALs and to mix DIALs with the derivatization regent.

11. Prepare the $10 \mathrm{pmol} \mu \mathrm{L}^{-1}$ of DIAL standard solution by adding $10.25 \mu \mathrm{L}$ of DIAL standard stock solution to a volumetric flask and make up to $1 \mathrm{~mL}$ with methanol. It makes it easier to take 20 pmol DIAL for the derivatization with a minimum amount of solvent.

12. Based on its MS response signal in UHPLC-Q-Orbitrtap MS, we use 20 pmol DIAL standard ( $2 \mu \mathrm{L}$ of DIAL standard solution) to prepare the DIAL standard derivatization solution. The amount of DIAL standard also need to be optimized for different LC-MS systems with different sensitivity.

13. To minimize the effect of free derivatization regent on MS, LC system was switched to waste channeldisconnected from MS system - in the first 6 min of the solvent gradient program. After 6 min, LC system was switched to MS system for detecting DIAL derivatives.

\section{Acknowledgments}

This work was supported by base line funding and a Competitive Research Grant (CRG4) given to Salim Al-Babili from the King Abdullah University of Science and Technology (KAUST).

\section{References}

[1] Cogdell BJ, Gillbro T, Andersson PO, Liu RSH, Asato AE (1994) Carotenoids as accessory lightharvesting pigments. Pure Appl Chem 66:1041-1046

[2] Horton P, Ruban AV, Walters RG (1996) Regulation of light harvesting in green plants. Annu Rev Plant Physiol Plant Mol Biol 47:655-684

[3] Ruban AV, Pascal AA, Robert B (2000) Xanthophylls of the major photosynthetic light-harvesting complex of plants: identification, conformation and dynamics. FEBS Lett 477:181-185

[4] Polívka T, Sundström V (2004) Ultrafast dynamics of carotenoid excited states-from solution to natural and artificial systems. Chem Rev 104:2021-2072 
[5] Fraser PD, Bramley PM (2004) The biosynthesis and nutritional uses of carotenoids. Prog Lipid Res 43:228-265

[6] Polívka T, Frank HA (2010) Molecular factors controlling photosynthetic light harvesting by carotenoids. Acc Chem Res 43:1125-1134

[7] Mendes-Pinto MM, Galzerano D, Telfer A, Pascal AA, Robert B, Ilioaia C (2013) Mechanisms underlying carotenoid absorption in oxygenic photosynthetic proteins. J Biol Chem 288:18758-18765

[8] Moise AR, Al-Babili S, Wurtzel ET (2014) Mechanistic aspects of carotenoid biosynthesis. Chem Rev 114:164-193

[9] Nisar N, Li L, Lu S, Khin NC, Pogson BJ (2015) Carotenoid metabolism in plants. Mol Plant 8:68-82

[10] Demmig-Adams B, Gilmore AM, Adams WW (1996) Carotenoids 3: in vivo function of carotenoids in higher plants. 3rd FASEB J 10:403-412

[11] Niyogi KK, Grossman AR, Bjorkman O (1998) Arabidopsis mutants define a central role for the xanthophyll cycle in the regulation of photosynthetic energy conversion. Plant Cell 10:1121-1134

[12] Pogson BJ, Niyogi KK, Bjorkman O, DellaPenna D (1998) Altered xanthophyll compositions adversely affect chlorophyll accumulation and nonphotochemical quenching in Arabidopsis mutants. Proc Natl Acad Sci USA 95:13324-13329

[13] Barber J, Anderson JM, Telfer A (2002) What is $\beta$-carotene doing in the photosystem II reaction centre? Phil Trans R Soc Lond B 357:1431-1440

[14] Jahns P, Holzwarth AR (2012) The role of the xanthophyll cycle and of lutein in photoprotection of photosystem II. BBA-bioenergetics 1817:182-193

[15] Ballottari M, Mozzo M, Girardon J, Hienerwadel R, Bassi R (2013) Chlorophyll triplet quenching and photoprotection in the higher plant monomeric antenna protein Lhcb5. J Phys Chem B. 117:11337-11348

[16] Hirschberg J (2001) Carotenoid biosynthesis in flowering plants, Curr Opin Plant Biol 4:210-218 
[17] Maresca JA, Graham JE, Bryant DA (2008) The biochemical basis for structural diversity in the carotenoids of chlorophototrophic bacteria. Photosynth Res 97:121-140

[18] Parry AD, Horgan R (1991) Carotenoids and abscisic acid (ABA) biosynthesis in higher plants. Physiol Plant 82:320-326

[19] Schwartz SH, Leon-Kloosterziel KM, Koornneef M, Zeevaart JA (1997) Biochemical characterization of the aba2 and aba3 mutants in Arabidopsis thaliana, Plant Physiol. 114:161-166

[20] Nambara E, Marion-Poll A (2005) Abscisic acid biosynthesis and catabolism. Annu Rev Plant Biol $56: 165-185$

[21] Abuauf H, Haider I, Jia KP, Ablazov A, Mi J, Blilou I, Al-Babili S (2018) The Arabidopsis DWARF27 gene encodes an all-trans-/9-cis- $\beta$-carotene isomerase and is induced by auxin, abscisic acid and phosphate deficiency. Plant Science 277:33-44

[22] Xie X, Yoneyama K, Yoneyama K (2010) The strigolactone story. Annu Rev Phytopathol. 48:93-117

[23] Alder A, Jamil M, Marzorati M, Bruno M, Vermathen M, Bigler P, et al (2012) The path from $\beta$-carotene to carlactone, a strigolactone-like plant hormone. Science 335:1348-1351

[24] Al-Babili S, Bouwmeester HJ (2015) Strigolactones, a novel carotenoid-derived plant hormone. Annu Rev Plant Biol 66:161-186

[25] Jia KP, Baz L, Al-Babili S (2018) From carotenoids to strigolactones. J Exp Bot 69:2189-2204

[26] Moise AR, Von Lintig J, Palczewski K (2005) Related enzymes solve evolutionarily recurrent problems in the metabolism of carotenoids. Trends Plant Sci 10:178-186

[27] Eroglu A, Harrison E H (2013) Carotenoid metabolism in mammals, including man: formation, occurrence, and function of apocarotenoids. J Lipid Res 54:1719-1730

[28] Grune T, Lietz G, Palou A, Ross AC, et al. (2010) $\beta$-Carotene is an important vitamin A source for humans. J Nutr 140:2268S-2285S 
[29] Austin DJ, Bu'lock JD, Drake D (1970) The biosynthesis of trisporic acids from b-carotene via retinal and trisporol. Experientia 26:348-349

[30] Medina HR, Cerdá-Olmedo E, Al-Babili S (2011) Cleavage oxygenases for the biosynthesis of trisporoids and other apocarotenoids in Phycomyces. Mol Microbiol 82:199-208

[31] Ramel F, Birtic S, Ginies C, Soubigou-Taconnat L, Triantaphylidès C, Havaux M (2012) Carotenoid oxidation products are stress signals that mediate gene responses to singlet oxygen in plants. Proc Natl Acad Sci USA 109:5535-5540

[32] Havaux M (2014) Carotenoid oxidation products as stress signals in plants. Plant J 79:597-606

[33] Lv F, Zhou J, Zeng L, Xing D (2015) $\beta$-cyclocitral upregulates salicylic acid signalling to enhance excess light acclimation in Arabidopsis. J Exp Bot 66:4719-4732

[34] Jia KP, Dickinson AJ, Mi J, Cui G, et al (2018) Anchorene is an endogenous diapocarotenoid required for anchor root formation in Arabidopsis. bioRxiv preprint doi: http://dx.doi.org/10.1101/496737

[35] Wang JY, Haider I, Jamil M, Fiorilli V, et al (2018) The apocarotenoid metabolite zaxinone regulates growth and strigolactone biosynthesis in rice. Nat Commun (Accepted).

[36] Demurtas OC, Frusciante S, Ferrante P, et al (2018) Candidate enzymes for saffron crocin biosynthesis are localized in multiple cellular compartments. Plant Physiol 177:990-1006

[37] Rodrigo MJ, Alquézar B, Alós E, Medina V, Carmona L, Bruno M, et al (2013) A novel carotenoid cleavage activity involved in the biosynthesis of Citrus fruit-specific apocarotenoid pigments. J Exp Bot 64:4461-4478.

[38] Estrada AF, Youssar L, Scherzinger D, Al-Babili S, Avalos J (2008) The ylo-1 gene encodes an aldehyde dehydrogenase responsible for the last reaction in the Neurospora carotenoid pathway. Mol Microbiol 69:1207-1220 
[39] Díaz-Sánchez V, Estrada AF, Trautmann D, Al-Babili S, Avalos J (2011) The gene carD encodes the aldehyde dehydrogenase responsible for neurosporaxanthin biosynthesis in Fusarium fujikuroi. FEBS J 278:3164-3176

[40] Beltran JC, Stange C (2016) Apocarotenoids: a new carotenoid-derived pathway. Subcell Biochem 79:239-272

[41] Frusciante S, Diretto G, Bruno M, Ferrante P, et al (2014) Novel carotenoid cleavage dioxygenase catalyzes the first dedicated step in saffron crocin biosynthesis. Proc Natl Acad Sci USA 111:1224612251

[42] Ilg A, Beyer P, Al-Babili S (2009) Characterization of the rice carotenoid cleavage dioxygenase 1 reveals a novel route for geranial biosynthesis. FEBS J 276:736-747

[43] Bruno M, Beyer P, Al-Babili S (2015) The potato carotenoid cleavage dioxygenase 4 catalyzes a single cleavage of $\beta$-ionone ring-containing carotenes and non-epoxidated xanthophylls. Arch Biochem Biophys 572:126-133

[44] Bruno M, Koschmieder J, Wuest F, Schaub P, Fehling-Kaschek M, Timmer J, et al (2016) Enzymatic study on AtCCD4 and AtCCD7 and their potential to form acyclic regulatory metabolites. J Exp Bot. 67:5993-6005

[45] Giuliano G, Al-Babili S, Von Lintig J (2003) Carotenoid oxygenases: cleave it or leave it. Trends Plant Sci 8:145-149

[46] Bouvier F, Isner JC, Dogbo O, Camara B (2005) Oxidative tailoring of carotenoids: a prospect towards novel functions in plants. Trends Plant Sci. 10:187-194

[47] Ilg A, Yu Q, Schaub P, Beyer P, Al-Babili S (2010) Overexpression of the rice carotenoid cleavage dioxygenase 1 gene in Golden Rice endosperm suggests apocarotenoids as substrates in planta. Planta 232:691-699

[48] Alder A, Holdermann I, Beyer P, Al-Babili S (2008) Carotenoid oxygenases involved in plant branching catalyse a highly specific conserved apocarotenoid cleavage reaction. Biochem J 416:289-296 
[49] Scherzinger D, Ruch S, Kloer DP, Wilde A, Al-Babili S (2006) Retinal is formed from apo-carotenoids in Nostoc sp. PCC7120: in vitro characterization of an apo-carotenoid oxygenase. Biochem J 398:361369

[50] Ilg A, Bruno M, Beyer P, Al-Babili S (2014) Tomato carotenoid cleavage dioxygenases 1A and 1B: Relaxed double bond specificity leads to a plenitude of dialdehydes, mono-apocarotenoids and isoprenoid volatiles. FEBS Open Bio 4:584-593

[51] Collins P (1992) The role of annatto in food colouring. Foods Ingred. Process. Int. 13:23-27

[52] Timberlake CF, Henry BS (1986) Plant pigments as natural food colours. Endeavour 10:31-37

[53] Palmer LS (1934) The biological and chemical nomenclature for the carotenoids. Science 79:488-490

[54] Bouvier F, Dogbo Odette, Camara Bilal (2003) Biosynthesis of the food and cosmetic plant pigment bixin (annatto). Science 300:2089-2091

[55] Mi J, Jia KP, Wang JY, Al-Babili S (2018) A rapid LC-MS method for qualitative and quantitative profiling of plant apocarotenoids. Anal Chim Acta 1035:87-95

[56] Tie C, Hu T, Jia ZX, Zhang JL (2016) Derivatization strategy for the comprehensive characterization of endogenous fatty aldehydes using HPLC-multiple reaction monitoring. Anal Chem 88:7762-7768 


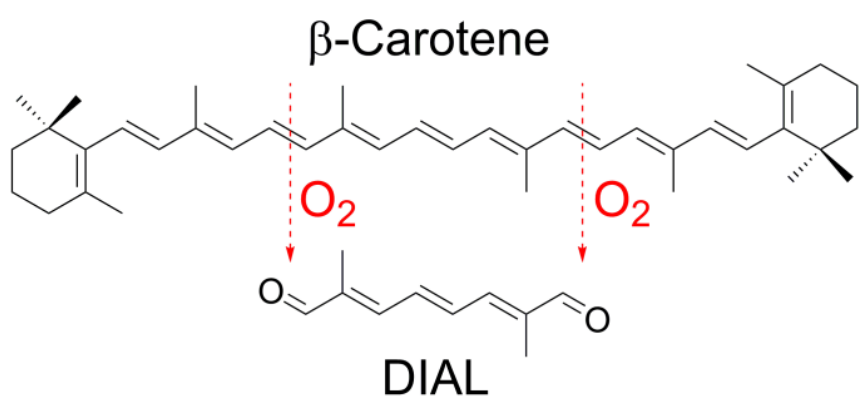

Figure 1: Structures of $\beta$-carotene and the generation of a representative carotenoid-derived DIAL. 


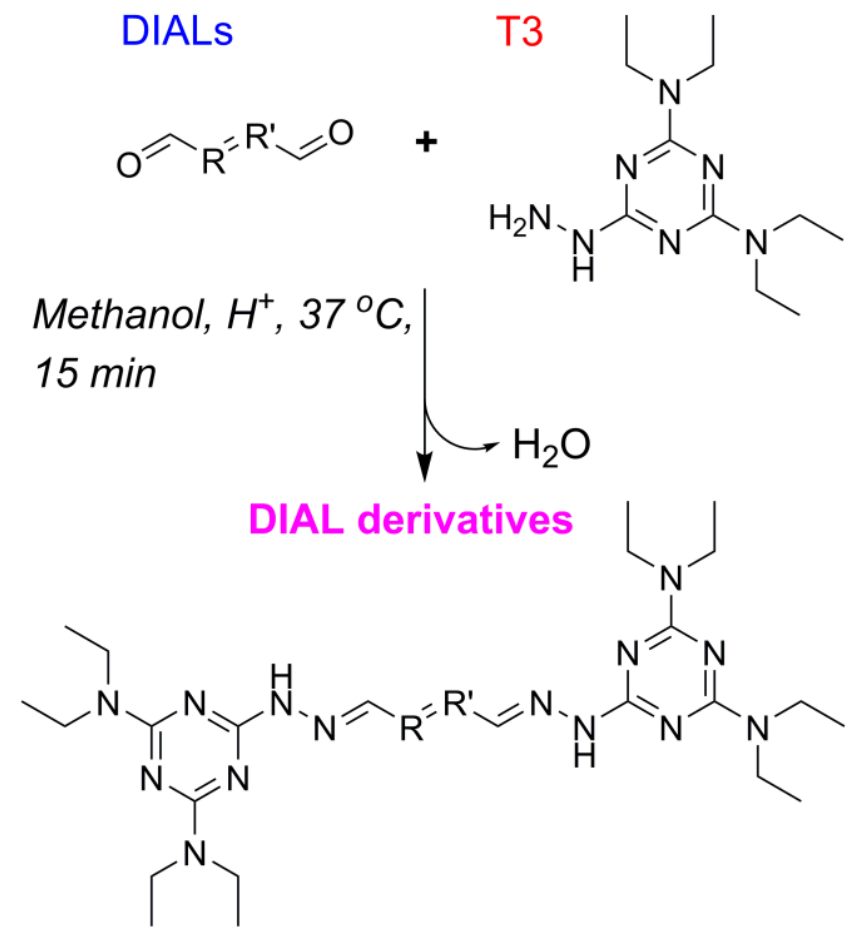

$R=R^{\prime}$ : Different double bond chains

Figure 2. Scheme of DIAL derivatization. 

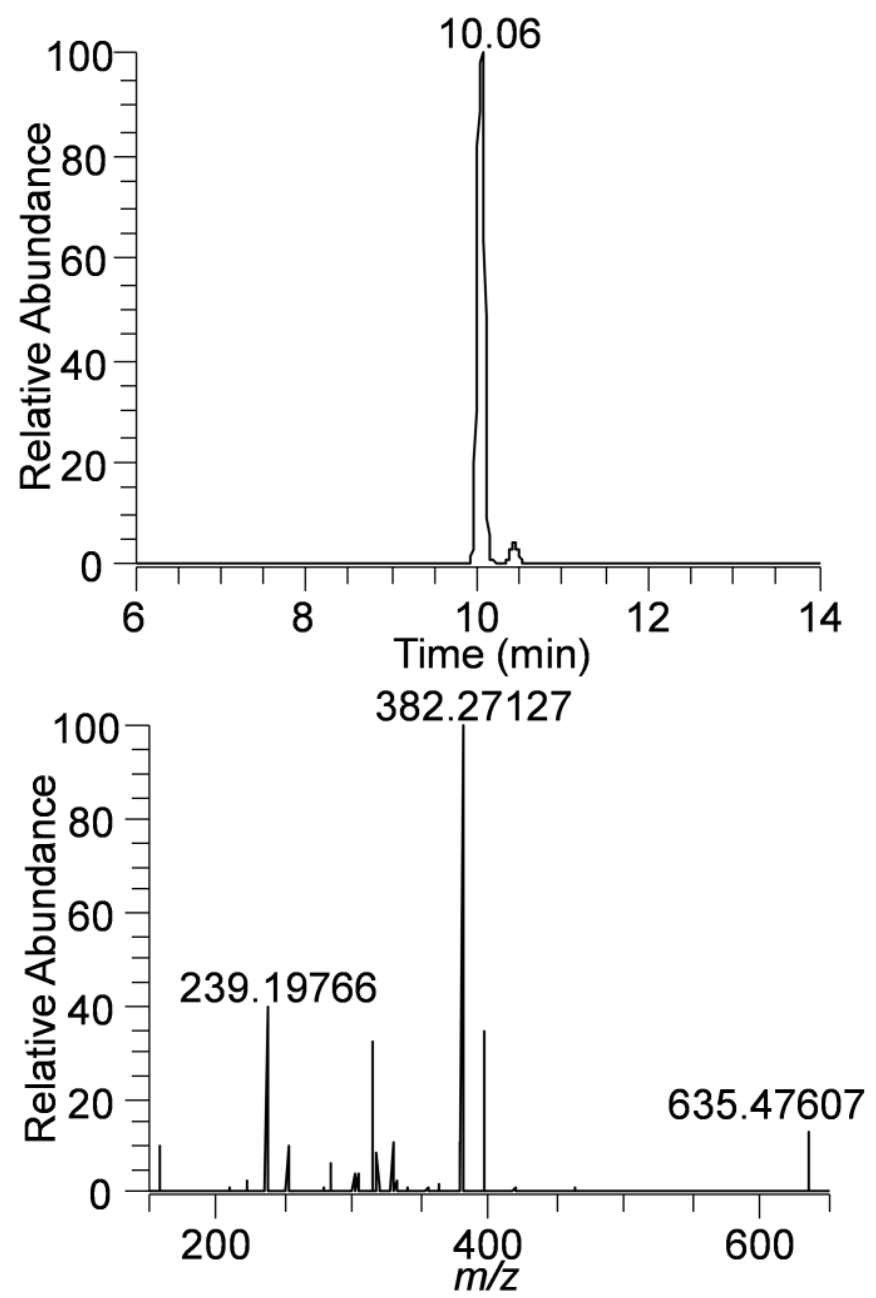

Figure 3. Identification of derivatized DIAL10 by using UHPLC-MS/MS. Extracted ion chromatogram of (upper) and MS/MS spectrum (down) of derivatized DIAL10. 